\title{
Household HIV/AIDS status and sexual debut among adolescents in Kenya
}

\author{
Monica Magadi ${ }^{1}$ and Rose Olayo ${ }^{2}$ \\ ${ }^{1}$ Department of Sociology, School of Social Sciences, City University \\ London, UK. monica.magadi.1@city.ac.uk \\ ${ }^{2}$ Tropical Institute for Community Health and Development ( $\left.\mathrm{TICH}\right)$, \\ Great Lakes University of Kisumu, Kenya.
}

This paper is part of a large-scale secondary analysis research project on HIV/AIDS and the well-being of children in sub-Saharan Africa, sponsored by the UK Medical Research Council.

\section{Abstract}

Adolescents in households affected by HIV/AIDS may be at an increased risk of poorer reproductive health than other adolescents due to the impoverishing effects of AIDS in households or lack of parental guidance. In this paper, we examine the effect of parents' HIV status on adolescent sexual and reproductive health, focusing on early sexual debut among adolescents in Kenya. The analysis places particular emphasis on comparisons of the relative disadvantage of different groups of adolescents aged 15- I 7 years, with particular reference to those living in households where an adult is infected with HIV. The data come from the 2003 and 2008 Kenya Demographic and Health Surveys (KDHS). The results suggest increased vulnerability among adolescent boys and girls living in households where an adult is infected with HIV, especially when other household factors are controlled for. On average, adolescent boys and girls living in households where at least one adult is infected with HIV have about $50 \%$ higher odds of having initiated sexual activity compared to their counterparts of similar age and gender in households where no adult is HIV positive. The odds are more than $60 \%$ higher when household characteristics and circumstances relating to wealth, household head and living arrangements are controlled for. Further analysis reveals that the observed vulnerability among adolescents living in households with HIV infected adults is partly explained by background factors relating to region of residence and ethnicity and to a lesser extent by school non-attendance and mass media exposure.

Key words: Adolescent sexual debut; adolescents affected by HIV/AIDS; Kenya; Demographic and Health Surveys; logistic regression models

\section{Introduction}

Background

The devastating impact of the HIV/AIDS pandemic in sub-Saharan Africa is most profoundly reflected in the lives of children, the most vulnerable members of families and communities. The scale of 
the AIDS orphans crisis is masked by the time lag between infection and death, implying that the crisis will continue to grow for many years, even in countries where HIV prevalence has started to decline. Orphans and vulnerable children are not necessarily young children and problems caused by orphaning extend well beyond age 15 , with available data suggesting that adolescents make up the majority of orphans in all countries (UNAIDS, UNICEF and USAID, 2004). The numbers of orphans reflect only a fraction of the number of children whose lives will have been radically affected by the impact of AIDS. Millions of other children are subjected to psychological distress, economic pressures and responsibilities of caring for ailing parents and siblings when the HIV-infected parents are still alive. HIV/ AIDS poses a significant threat to adolescents' health and life prospects in subSaharan Africa where AIDS has become the single largest cause of disease/death (UNAIDS and WHO, 2009). Early adolescent sexual onset is of public health importance because it contributes to ill sexual and reproductive health by elevating the risk of unintended pregnancies and sexually transmitted diseases (STDs). Early sexual debut increases young peoples' risk for infection with HIV and other STIs because youth who initiate sexual activity early are likely to have multiple sex partners (Mott et al., 1996) and less likely to use condoms (Enaik et al., 2002).

HIV/AIDS can have devastating effects on households and, subsequently, on the lives of children and adolescents across the continent. The mechanisms through which the pandemic affects adolescents' prospects are multiple and complex, ranging from the effects of orphanhood to those of residence in a household impoverished by AIDS-related illnesses and/or opportunistic infections. When parents fall sick, particularly in poor families, most children end up in income-generating activities after dropping out of school. Many children orphaned by AIDS lose their childhood and are forced by circumstances to become producers of income or food, or caregivers for sick family members. In many cases, such children become increasingly vulnerable to malnutrition, abuse, exploitation, and ill-health, including early initiation of sexual activity (Mmari, 20l0).

A number of recent studies in various Southern Africa settings have observed greater sexual risk (ever had sex, ever pregnant) among orphans than non-orphans (Thurman, et al., 2006; Operario et al., 2007; Nyamukapa et al., 2008; Birdthistle et al., 2009). Birdthistle et al., (2009) noted that educational status explained only a small part of double orphans sexual risk and that additional research is needed to identify other socio-economic and emotional factors driving orphans sexual risk so that prevention and support programmes can meet the needs of this growing population. Although there has been considerable attention on vulnerability of AIDS orphans, few studies have examined sexual risk among other adolescents adversely affected by HIV/ AIDS, such as those whose parents (or other adult household members) are living with AIDS.

Adolescents in households affected by HIV/AIDS may be at an increased risk of poorer sexual and reproductive health outcomes than other adoles- 
cents due to the impoverishing effects of AIDS in households or lack of parental guidance. It has been argued that adolescents from intact family structures are less likely to engage in highrisk sexual behaviour such as early sexual debut or transactional sex than their counterparts from non-intact families, including homes destabilized or impoverished by HIV/AIDS (Enaik et al., 2002; Oman et al., 2005; Sturgeon, 2008). The assumption here is that the HIV/ AIDS pandemic is likely to lead to unfavorable adolescent sexual outcomes through the effects of either lack of significant parental monitoring or lack of perception of parental affection and support (Lammers et al., 2000; Oman et al., 2005). Findings from a recent qualitative research in Tanzania revealed three important care giving roles that contributed to adolescent health: the provision of basic needs, advising and monitoring adolescent behaviors, and assigning household chores. Adolescent participants believed that when these roles are compromised, female orphans' sexual behaviors are impacted (Mmari, 20I0). A US study on young adolescents from ethnic minority low income families living in inter-city communities observed no difference in risk behaviours between youth with and without HIV infected mothers. However, among youth with HIV positive mothers, those who knew their mothers status had more thought problems and reported more frequent alcohol use (Mellins et al., 2005).

Since all children whose lives are affected by HIV/AIDS are not vulnerable to miserable life and ill-health, it is important to understand the factors that place adolescents at risk of ill sexual and reproductive health. In this study, we use information from population-based sample surveys conducted in a typical sub-Saharan African setting, Kenya, to identify HIV/AIDS factors that make adolescents vulnerable to early sexual debut in such settings. An analysis of the determinants of early sexual debut in a setting adversely affected by the HIV/AIDS pandemic is set to be of benefit to public health practice because it provides the possibility of understanding the extent to which the devastating impact of the pandemic is reflected in poor and unfavorable adolescent sexual outcomes.

\section{Aims and objectives}

In this paper, we examine the effect of HIV status of adult household members on adolescent sexual debut. The specific objectives are:

- examine the link between HIV status of adult household members and early sexual debut among adolescents in Kenya; and

-

- establish the role of background socio-economic, demographic and cultural factors in explaining the observed associations between household HIV status and early sexual debut among adolescents.

The analysis places particular emphasis on gender disparities in the link between household HIV/AIDS status and adolescent sexual/reproductive health.

\section{Data and methods}

The data used in this study come from the 2003 and 2008 Kenya Demographic and Health Surveys (KDHS). Both data- 
sets provide a unique opportunity to anonymously link the individual/household survey data with the HIV testing data at individual level, enabling an examination of the association between a range of demographic and socio-economic characteristics and HIV infection. The analysis focuses on never married adolescents aged 15-17 years. In each of the surveys, the combined sample of never married adolescent boys and girls aged $15-17$ years is about 800 , providing sufficient samples for analysis of the determinants of sexual debut.

The analysis is based on single-level logistic regression models. Multilevel logistic regression models were explored to take into account random community (cluster) effects but there was no evidence of potential clustering of sexual debut within clusters. Hence, the final models presented were based on single-level logistic regression analyses.

The dependent variable measures early initiation of sexual intercourse among adolescents. It is included in the analysis as a dichotomous variable coded "I" if an adolescent aged I5-I7 years has ever had sexual intercourse and "0" otherwise. We focus on early sexual debut because research has consistently identified an association between early age at first sex and involvement in several kinds of socially unacceptable activities such as school absenteeism, premarital sexual activity, fighting and use of controlled substances (Mott et al., 1996). Early sexual debut increases young people's risk of infection with HIV and other STIs because people who begin having intercourse at younger ages are expected to be more likely to engage in unprotected sexual intercourse with casual partners and to have multiple and concurrent partnerships (Mott et al., 1996; Enaik et al., 2002). Condom use may be effective in casual relationships when the age gap between partners is relatively small, but can be extremely challenging in cross-generational and transactional relationships.

The key explanatory variables used as an indicator for household HIV/AIDS status is HIV status of adult household members, coded as " $I$ " if at least one adult household member is HIV positive, and " 0 " otherwise. The covariates controlled for in the analyses include: individual demographic, socio-economic and cultural factors (e.g. age, school enrolment, educational attainment, media exposure, urban/rural residence, religion); and household factors, including socio-economic status (wealth index), gender of household head, and living arrangements. These covariates are introduced to the models in successive stages to establish potential pathways of the determinants, starting with the household HIV/AIDS while controlling for age and sex, followed with other household factors, before introducing the individual socio-economic and cultural characteristics. We postulate that the covariates included in the model can help explain the sexual risk associated with presence of HIV infected adults in households.

One of the data quality concerns relate to possible selectivity bias in DHS HIV testing. The DHS targets nationally representative random samples for HIV testing and although overall response rates for both 2003 and 2008 Kenya DHS are reasonable at more than $70 \%$, possible bias may result if non-response 
is selective by key characteristic. If nonresponse cases are random, then those missing HIV/AIDS testing are unlikely to distort the patterns of associations observed. However, of particular concern are those who refused HIV testing. This group may represent a select subgroup with respect to key characteristics associated with HIV sero-status. An earlier detailed analysis of factors associated with refusal for HIV testing showed overall little evidence of systematic selectivity by key factors associated with HIV sero-status. The apparent lack of evidence of significant associations between refusal of HIV testing and demographic factors such as age, marital status and sexual activity (Magadi and Agwanda, 2007) is somewhat re-assuring, given the expected strong association between these factors and HIV sero-status.

\section{Bivariate analysis}

The analysis starts with an examination of the bivariate distribution of the proportion of never-married adolescent boys and girls aged 15-17 who have ever had sex, classified by whether or not they live in households where an adult is infected with HIV and other background characteristics based on 2003 and 2008 KDHS data (Table I).

The bivariate patterns in Table I, based on the 2003 and 2008 KDHS, suggest that for both boys and girls, the proportion of never-married adolescents aged 15-17 who have initiated sexual activity is generally higher among those living in households where an adult is HIV positive than in households where no adult is infected. However, the association is only significant for males based on the 2003 KDHS, presumably due to the small sample sizes and low statistical power to detect significance. Despite the relatively low statistical power, there is evidence in both surveys of significant variations in sexual debut by school attendance, region of residence and ethnicity for both adolescent boys and girls. In particular, a considerably high proportion of adolescents who are out of school, or living in Nyanza Province or of Luo ethnic background have initiated sexual activity by age 15-17.

The bivariate association between sexual debut and HIV status of adult household members observed in Table $\mathrm{I}$ is likely to be affected by other factors, associated with both sexual debut and household HIV status. In the next section, we examine the independent association, simultaneously controlling for the effect of other significant factors in a multivariate analysis.

\section{Multivariate analysis}

Since the association patterns observed in Table I are relatively consistent by sex and survey, the multivariate analysis combines the data for adolescent boys and girls across the two surveys for increased statistical power. All models control for the effect of the individual's age and gender as well as survey year. The results of logistic regression analysis of the association between HIV status of adult household members and adolescent sexual debut are presented in Table 2. The first model only controls for survey year and the effect of basic demographic factors relating to gender and age of adolescent (Model I). 
African Population Studies Vol 25, 2 (Dec 20II)

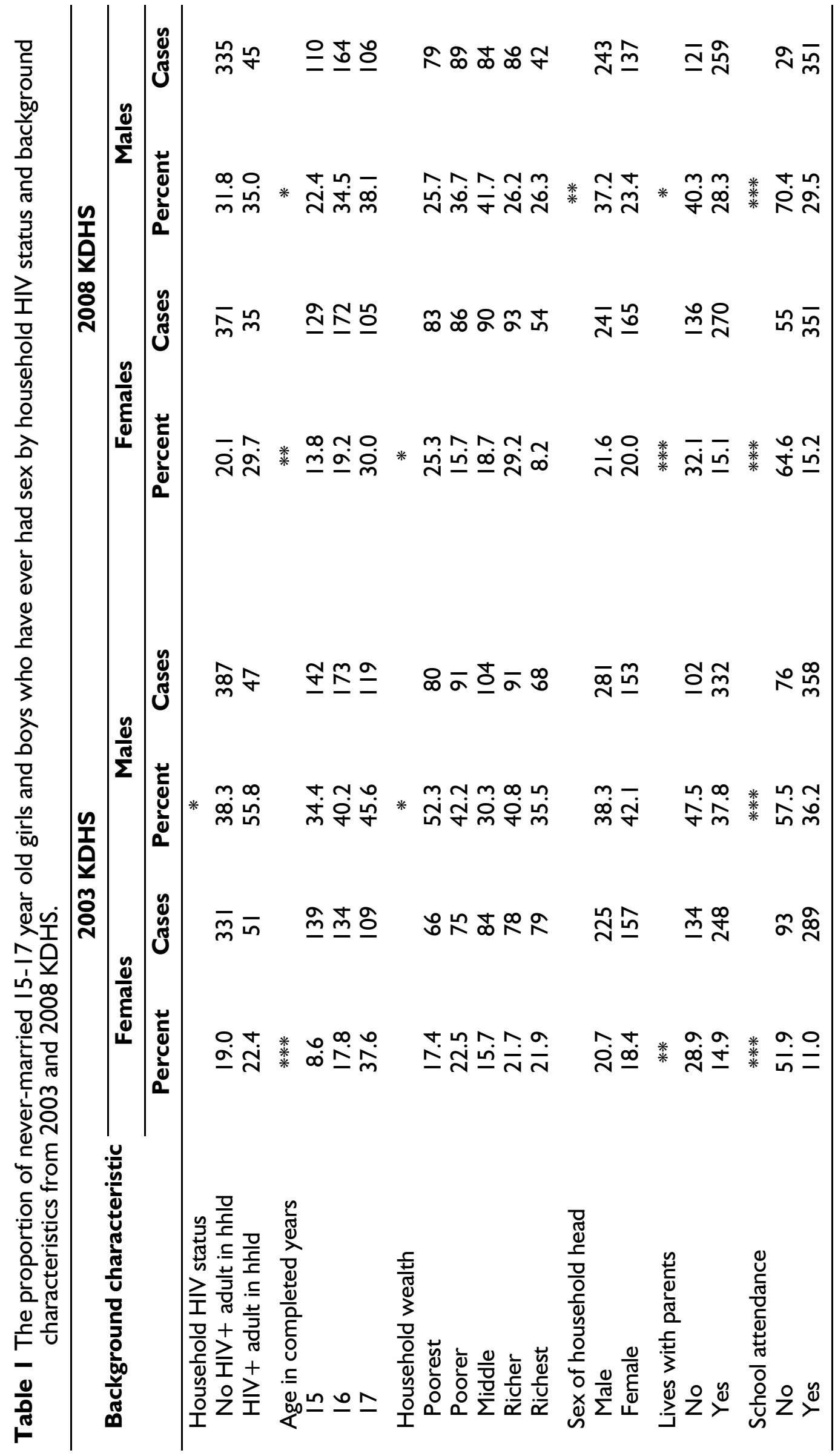




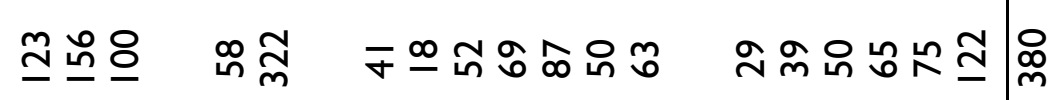

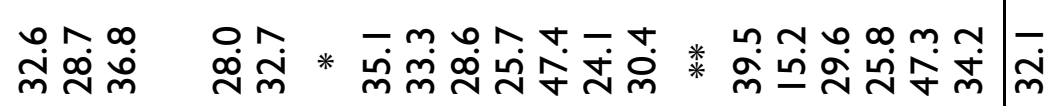

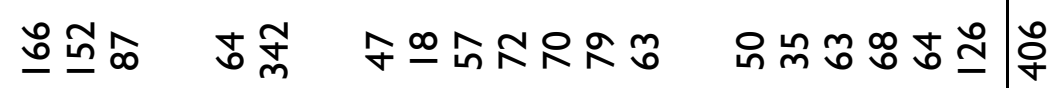

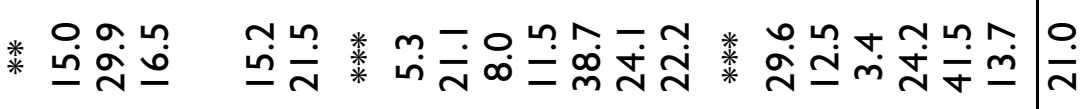

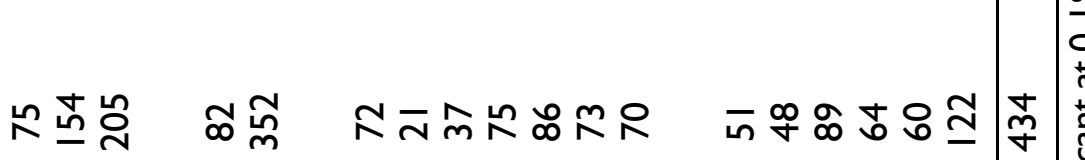

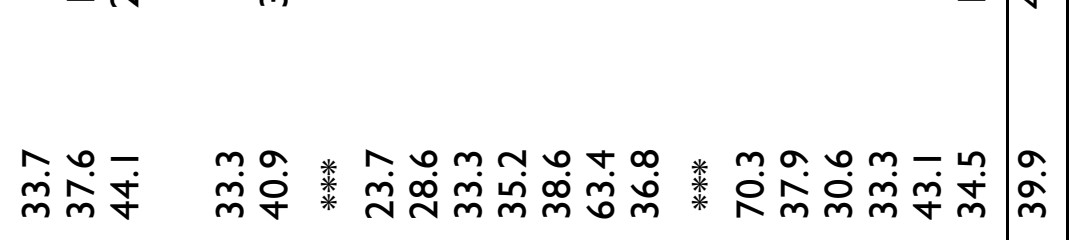

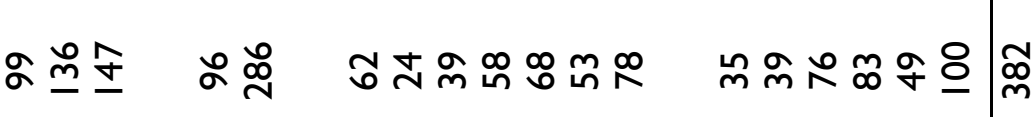

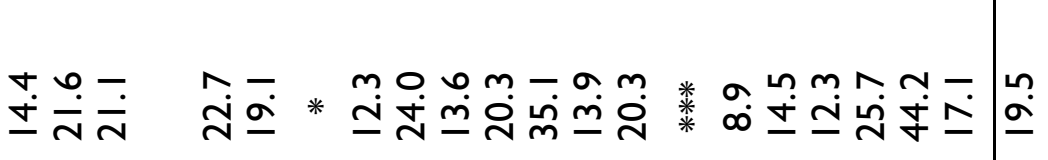


This is followed by: a second model taking into account the effect of other household factors relating to wealth, gender of household head and whether the adolescent lives with parents (Model 2); a third model taking into account individual characteristics with respect to school attendance and mass media exposure (Model 3); and a fourth and final model taking into account broad/contextual background factors relating to area of residence and ethnicity (Model 4).

The multivariate results in Table 2 provide strong evidence for vulnerability of adolescents living in households where at least one adult is living with HIV. On average, adolescents living in households where at least one adult is HIV-infected are about 50\% more likely to have initiated sexual activity compared to their counterparts of similar sex and age who are living in household where no adult is infected with HIV. The higher risk among adolescents living in households with HIV-infected adults increases to over $60 \%$ when household factors relating to wealth, gender of household head and whether or not the adolescent lives with parent(s) are controlled for. The higher risk of sexual debut among adolescents living in households with HIV-infected adults is partly explained by school nonattendance and mass media exposure. When these factors are introduced to the model, the higher risk among adolescents in households where an adult is infected with AIDS, relative to those in households where no adult is infected, is reduced by 10 percentage points from $64 \%$ to $54 \%$. To a larger extent, part of the higher risk of early sexual debut among adolescents in households with HIV infected adults is explained by broader background characteristics relating to region of residence and ethnicity - the relationship ceases to be significant when these factors are controlled for.

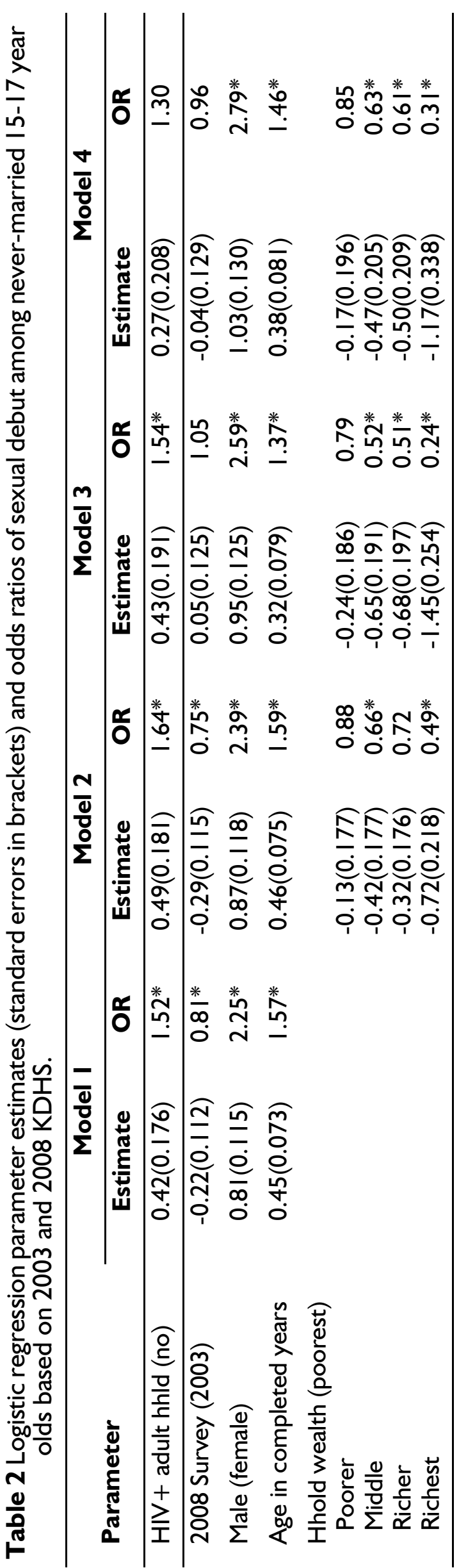




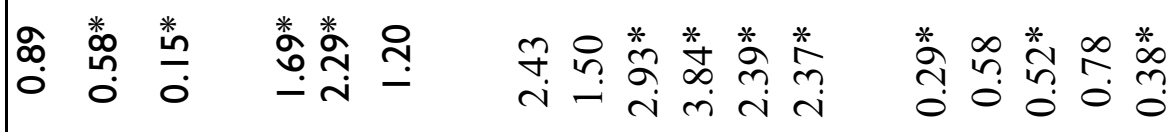

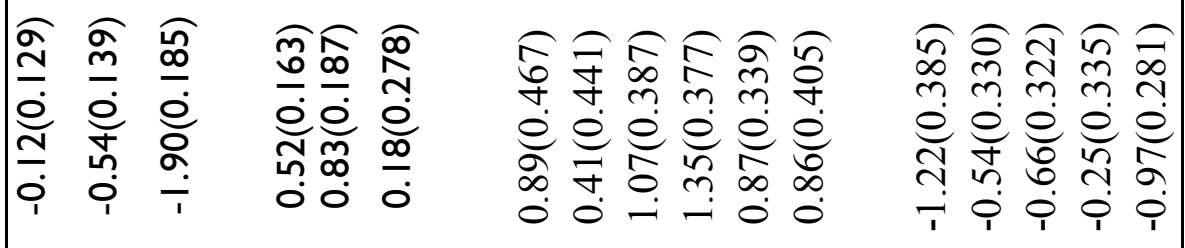

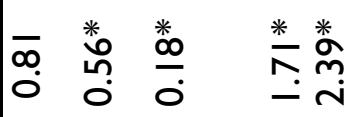

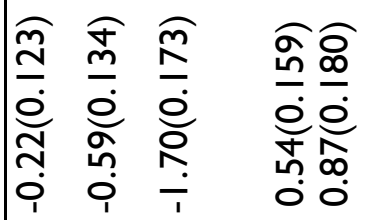

\begin{tabular}{ll}
$*$ \\
\multirow{2}{*}{} & $\frac{*}{\infty}$ \\
0 & $\stackrel{0}{0}$
\end{tabular}

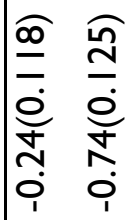

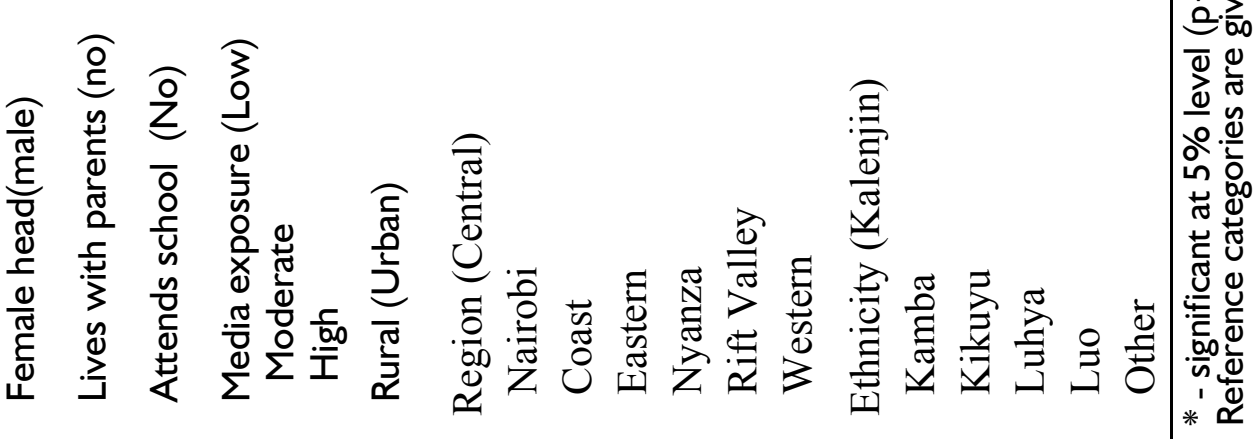


The association between sexual debut and other covariates included in the analysis largely conform to what might be expected. There was a significant reduction in the odds of having initiated sexual activity between 2003 and 2008, solely attributable to adolescents staying in school longer in 2008. Adolescent boys aged 15-17 years are more than twice as likely to have initiated sexual activity than their female counterparts of similar age. In fact, the gender disparity is wider when individual/household and contextual background socio-economic characteristics are controlled for. For instance, compared to their female counterparts of the same ethnic background, from the same region and of similar schooling status and mass media exposure, adolescent boys aged 15-17 years have an almost three times (i.e 2.8 times) higher odds of having initiated sexual activity. As expected, the odds of having initiated sexual activity consistently increases with age. The results suggest that an increase in age by one year between age 15-17 is associated with an almost 60 percent increase in the odds of initiating sexual activity when household circumstances are controlled for. The higher odds of sexual debut among older adolescents is partly explained by them being more likely to be out of school and have higher mass media exposure, factors associated with increased risk of sexual debut. Besides HIV status of adult household members, other household factors significantly associated with adolescent sexual debut include household wealth, gender of household head and living arrangements. There is a significant reduction in the odds of having initiated sexual activity with increasing household wealth.
The household socio-economic inequality is increased when adolescent school attendance and mass media exposure are controlled for. For instance, compared to their counterparts of similar schooling status, mass media exposure and background demographic characteristics, adolescents in the poorest quintile households are about four times more likely to have initiated sexual activity than those in the richest households. It is interesting to note that adolescents in female headed households generally have lower odds of having initiated sexual activity, although this ceases to be significant when other factors such as schooling status, mass media exposure, region of residence and ethnicity are controlled for. As might be expected, adolescents living with parents are significantly less likely to have initiated sexual activity than their counterparts living independently or with other relatives or foster families.

Schooling status is perhaps the most significant factor in adolescent sexual debut. Being in school is associated with a substantial reduction in the odds of 15-17 year olds having initiated sexual activity, with those out of school having odds more than five times higher when other important factors are controlled for. On the other hand, higher exposure to mass media is associated with a significant increase in the odds of having initiated sexual activity. Although mass media exposure is expected to be associated with urban/rural residence, there is no evidence of a significant difference between rural and urban residence, suggesting that it is exposure to mass media, rather than residence per se that is associated with the risk of sexual debut.

Significant variations exist in the 
odds of sexual activity among adolescents by region of residence and ethnicity. Nyanza Province is associated with the highest odds of 15-17 year old adolescents having initiated sexual activity while Central Province has the lowest odds. The results suggest that adolescents in Nyanza Province have almost four times higher odds of having initiated sexual activity than their counterparts of similar characteristics in Central Province. The patterns of sexual debut by ethnicity suggest that the Kalenjins have the highest odds while the Kambas have the lowest odds of having ever had sex.

\section{Discussion and conclusions}

The main objectives of this paper were to examine the link between HIV status of adult household members and early sexual debut among adolescents in Kenya, and establish the role of background socio-economic, demographic and cultural factors in explaining the observed associations between household HIV status and early sexual debut among adolescents. The results provide evidence of a significant association between household HIV status and sexual debut of 15-17 year old never-married adolescents in Kenya. On average, adolescent boys and girls living in households where at least one adult is infected with HIV have about 50 percent higher odds of having had sex compared to their counterparts of similar age and gender in households where no adult is infected with HIV. The odds are about 60 percent higher when household characteristics and circumstances relating to wealth, household head and living arrangements are controlled for. The fact that richer house- holds are associated with a generally lower risk of sexual debut (see Table I), but a higher risk of HIV infection (see Table Al in the Appendix) implies that the independent association between HIV household status and sexual debut becomes more apparent when household wealth is controlled for.

The analysis further reveals that the observed vulnerability among adolescents living in households with HIV infected adults is partly attributable to school non-attendance and mass media exposure, and to a larger extent to contextual background factors relating to region of residence and ethnicity. The higher risk of sexual debut among adolescents living in households with HIVinfected adults is to some extent explained by school non-attendance and mass media exposure, factors associated with higher risks of both sexual debut (see Table I) and HIV prevalence (see Table Al in Appendix). It is not surprising that the vulnerability among adolescents in households where an adult is infected with HIV is largely accounted for by regional and ethnic variations, especially since the regions with the highest HIV prevalence such as Nyanza province (see Table AI in Appendix), also tend to be associated with earlier sexual debut (see Table I).

The patterns showing higher risk sexual behavior among adolescents living in households where an adult is infected with HIV are consistent with patterns for adolescent orphans observed in recent studies in various Southern Africa settings where greater sexual risk (ever had sex, ever pregnant) was observed among orphans than non-orphans (Thurman, et al., 2006; Operario et al., 2007; Nyamu- 
kapa et al., 2008; Birdthistle et al., 2009). It is possible that HIV infection among adults is households will lead to an increased risk of adolescents engaging in high-risk sexual behaviors due to homes being destabilized or impoverished by HIV/AIDS (Enaik et al., 2002; Oman et al., 2005; Sturgeon, 2008). As noted earlier, the argument here is that the HIV/AIDS pandemic is likely to lead to unfavorable adolescent sexual outcomes through the effects of either lack of significant parental monitoring or lack of perception of parental affection and support (Lammers et al., 2000; Oman et al., 2005).

The findings observed in this paper have important implications for interventions to address adolescent sexual and reproductive health in settings devastated by HIV/AIDS such as Kenya and similar settings in sub-Saharan Africa. The fact that being in school is perhaps the most important protective factor for adolescent high risk sexual behaviour highlights the importance of programmes aimed at addressing educational or schooling opportunities for children from households affected by HIV/AIDS. The results presented here suggest that it is crucial for existing programmes targeting orphans to be extended to other children living in households affected by HIV/AIDS, especially those whose parents are living with AIDS.

We recognize the importance of more detailed analysis of gender disparities in the risk factors and therefore recommend further analysis to generate findings that would inform gender specific interventions. In particular, previous studies have noted important gender differences in adolescent sexual health with respect to living arrangements (Ngom et al, 2004) and household wealth (Magadi, 20II) that would be important to explore further in relation to the devastating impact of HIV/ AIDS on households.

\section{References}

Birdthistle, I. J., Floyd, S., Nyagadza, A., Mudziwapasi, N., Gregson, S., \& Glynn, J. R. (2009). "Is education the link between orphanhood and HIV/ HSV-2 risk among female adolescents in urban Zimbabwe?" Social Science and Medicine, 68: 1810-1818.

Enaik E, Patel MP, Persad AS, Westhoff W, Galwankar S. (2002) "Adolescent high-risk sexual behavior in the Dominican Republic: an assessment of familial factors, International Conference on AIDS" Int Conf AIDS.

Lammers, C.M.I., Resnick M.D., and Blum R.W. (2000). "Influences on Adolescents' Decision to Postpone Onset of Sexual Intercourse: A Survival Analysis of Virginity Among Youths Aged 13 to 18 Years," Journal of Adolescent Health, 26(I): 40-48.

Magadi M. A. (20II). "Understanding the gender disparity in HIV infection in sub-Saharan Africa: evidence from the DHS". Sociology of Health and Illness 33(4): 522-539.

Magadi M. A. and A. Agwanda (2007) "The link between HIV/AIDS and recent fertility patterns in Kenya" Measure Evaluation Working Paper WP-07-92. https://www.cpc.unc.edu/ measure/publications/pdf/wp-07$\square 2 . p d f$

Mellins, CA., E. Brackis-Cott, C. Dolezal and HFL. Meyer-Bahlburg (2005). "Behavioral risk in early 
adolescents with HIV+ mothers “ Journal of Adolescent Health, 36(4):342-35I.

Mmari, K. (20/0). "Exploring the relationship between caregiving and health: Perceptions among orphaned and non-orphaned adolescents in Tanzania " Journal of Adolescence. Available online June 2010, doi:10.1016/j.adolescence. 2010.05.001.

Mott, F.L., Fondell, M.M., Hu, P.N., Kowaleski-Jones, L. and Menaghan, E.G. (1996) "The Determinants of First Sex by Age 14 in a High-Risk Adolescent Population," Family Planning Perspectives, 28:13-18.

Ngom, P., Magadi, M. A., and Owuor, T., (2003) "Parental Presence and Adolescent Reproductive Health among the Nairobi Urban Poor" Journal of Adolescent Health 33(5): 369-377.

Nyamukapa, C. A., Gregson, S., Lopman, B., Saito, S., Watts, H. J., Monasch, R., et al.

(2008). HIV-associated orphanhood and children's psychosocial distress: theoretical framework tested with data from Zimbabwe. American Journal of Public Health, 98(I): 133I4I.

Operario, D., Pettifor, A., Cluver, L.,
MacPhail, C., \& Rees, H. (2007). "Prevalence of parental death among young people in South Africa and risk for HIV infection" Journal of Acquired Immune Deficiency Syndromes, 44(I): 93-98.

Oman R.F., Vesely S.K., and Aspy C.B. (2005) Youth assets and sexual risk behavior: The importance of assets for youth residing in one-parent households. Perspect Sex Reprod Health 37: 25-31.

Sturgeon SW, 2008, "The Relationship Between Family Structure and Adolescent Sexual Activity," Produced by familyfacts.org (www.familyfacts.org), The Heritage Foundation

Thurman, T. R., Brown, L., Richter, L., Maharaj, P., \& Magnani, R. (2006)."Sexual risk behavior among South African adolescents: is orphan status a factor?" AIDS Behaviour, 10(6): 627-635.

UNAIDS, UNICEF and USAID (2004) Children on the Brink 2004: A joint report of the new orphan estimates and a framework for action. http:// www.unicef.org/publications/files/ cob_layout6-013.pdf

UNAIDS and WHO (2009) AIDS Epidemic Update December 200ワ. UNAIDS, Geneva 


\section{Appendix}

Table AI Percent of analysis sample in households where an adult is HIV positive by background characteristics

\begin{tabular}{|c|c|c|}
\hline \multirow[t]{2}{*}{ Background characteristic } & \multicolumn{2}{|c|}{ Adult in household HIV+ } \\
\hline & Percent & Cases \\
\hline $\begin{array}{l}\text { Year of survey } \\
2003 \\
2008\end{array}$ & $\begin{array}{r}11.0 \\
9.4\end{array}$ & $\begin{array}{l}816 \\
786\end{array}$ \\
\hline $\begin{array}{l}\text { Sex of respondent } \\
\text { Female } \\
\text { Male }\end{array}$ & $\begin{array}{r}10.9 \\
9.4\end{array}$ & $\begin{array}{l}788 \\
814\end{array}$ \\
\hline $\begin{array}{l}\text { Age in completed years } \\
15 \\
16 \\
17\end{array}$ & $\begin{array}{r}10.8 \\
9.5 \\
10.2\end{array}$ & $\begin{array}{l}520 \\
643 \\
439\end{array}$ \\
\hline $\begin{array}{l}\text { Household wealth } \\
\text { Poorest } \\
\text { Poorer } \\
\text { Middle } \\
\text { Richer } \\
\text { Richest }\end{array}$ & $\begin{array}{r}* \\
5.3 \\
10.3 \\
10.6 \\
12.8 \\
10.8\end{array}$ & $\begin{array}{l}308 \\
341 \\
362 \\
348 \\
243\end{array}$ \\
\hline $\begin{array}{l}\text { Sex of household head } \\
\text { Male } \\
\text { Female }\end{array}$ & $\begin{array}{r}9.1 \\
11.9\end{array}$ & $\begin{array}{l}990 \\
612\end{array}$ \\
\hline $\begin{array}{l}\text { Lives with parents } \\
\text { No } \\
\text { Yes }\end{array}$ & $\begin{array}{r}9.4 \\
10.5\end{array}$ & $\begin{array}{r}493 \\
1109\end{array}$ \\
\hline $\begin{array}{l}\text { School attendance } \\
\text { No } \\
\text { Yes }\end{array}$ & $\begin{array}{r}12.4 \\
9.8\end{array}$ & $\begin{array}{r}253 \\
1349\end{array}$ \\
\hline $\begin{array}{l}\text { Exposure to mass media } \\
\text { Low } \\
\text { Moderate } \\
\text { High }\end{array}$ & $\begin{array}{r}* \\
8.1 \\
9.2 \\
13.0\end{array}$ & $\begin{array}{l}465 \\
598 \\
539\end{array}$ \\
\hline $\begin{array}{l}\text { Residence } \\
\text { Urban } \\
\text { Rural }\end{array}$ & $\begin{array}{r}* \\
13.9 \\
9.5\end{array}$ & $\begin{array}{r}300 \\
1302\end{array}$ \\
\hline $\begin{array}{l}\text { Region } \\
\text { Central } \\
\text { Nairobi } \\
\text { Coast } \\
\text { Eastern } \\
\text { Nyanza } \\
\text { Rift Valley } \\
\text { Western }\end{array}$ & $\begin{array}{r}* * * * \\
9.1 \\
14.5 \\
6.9 \\
8.5 \\
20.3 \\
3.8 \\
9.9\end{array}$ & $\begin{array}{r}222 \\
81 \\
185 \\
274 \\
311 \\
255 \\
274\end{array}$ \\
\hline $\begin{array}{l}\text { Ethnic group } \\
\text { Kalenjin } \\
\text { Kamba } \\
\text { Kikuyu } \\
\text { Luhya } \\
\text { Luo } \\
\text { Other }\end{array}$ & $\begin{array}{r}* * * \\
2.3 \\
13.9 \\
6.7 \\
10.1 \\
26.8 \\
4.9\end{array}$ & $\begin{array}{l}165 \\
161 \\
278 \\
280 \\
248 \\
470\end{array}$ \\
\hline All & 10.2 & 1602 \\
\hline
\end{tabular}

